\title{
THE EFFECTIVENESS OF THE 55 MPH NATIONAL \\ - MAXIMUM SPEED LIMIT AS A LIFE SAVING BENEFIT Executive Summary
}

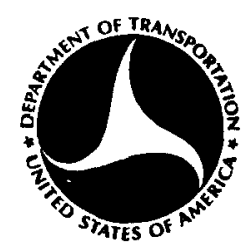

Prepared by

U.S. DEPARTMENT OF TRANSPORTATION

National Highway Traffic Safety Administration

Office of State Vehicle Programs

January 1981 
Technical Report Documentation Page

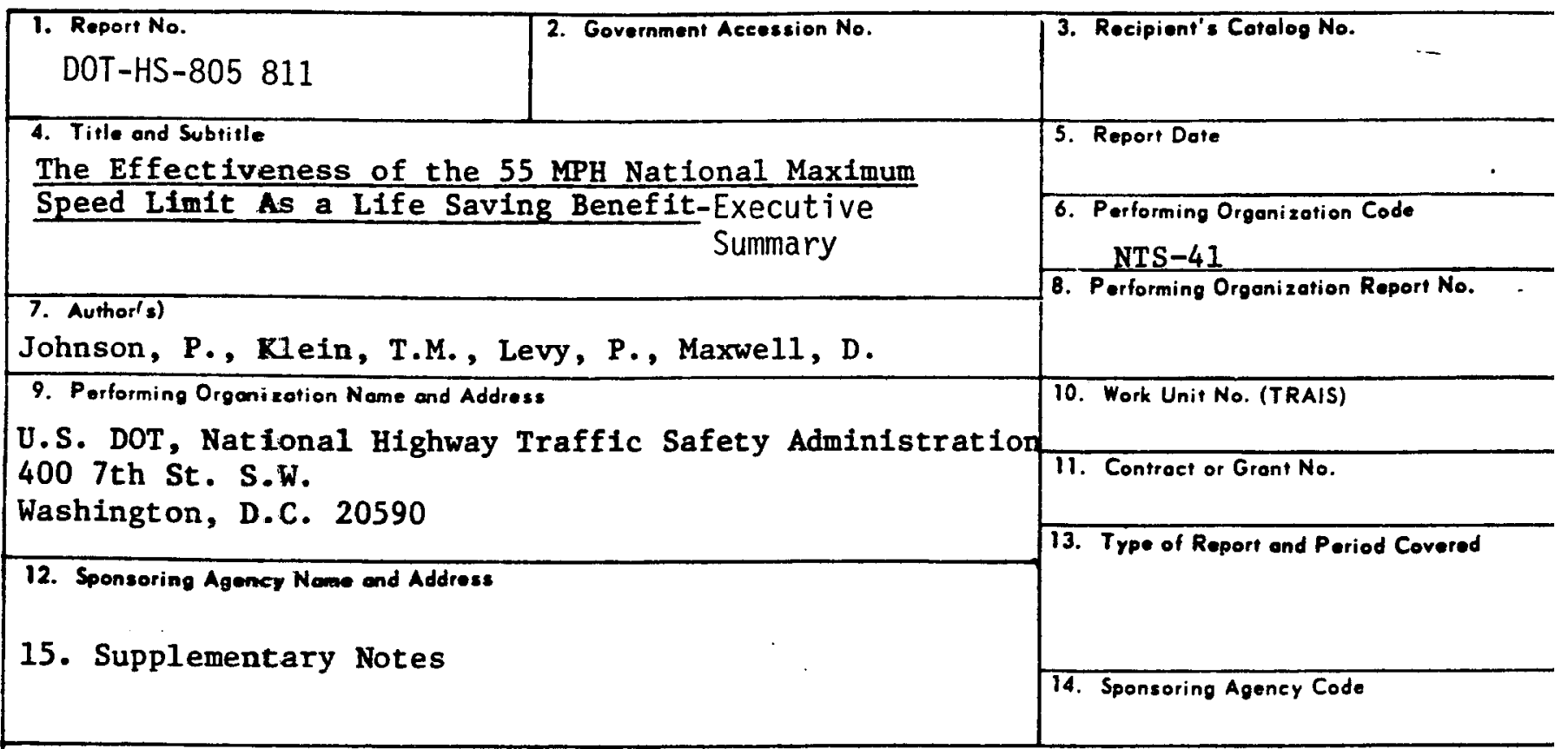

\section{Abstract}

The following report contains an analysis of the life saving benefits resulting from the 55 mph NMSL from 1974-1979. Monthly fatal1ty data from 1970-1979 was used in a time series model to arrive at the estimated safety benefits (1ives saved). The time series model relates changes in monthly fatalities to changes in monthly vehicle miles traveled, Introduction of safety improvements and the implementation of the $55 \mathrm{mph}$ MMSL law. Increases in highway fatalities in 1976-1979 compared to the 1974-1975, level led to a detailed examination and analysis of the composition of these fatalities in order to determine possible causes for the increases. Based upon the available data, it was concluded that $55 \mathrm{mph}$ compliance had eroded somewhat in 1977 and 1978 thus resulting in some fatality increases. The statistical time series model estimated annual life saving benefits as follows:

\section{LIVES SAVED}

$\begin{array}{lr}1974 & 7,532 \\ 1975 & 7,532 \\ 1976 & 7,216 \\ 1977 & 6,794 \\ 1978 & 6,423 \\ 1979 & 6,454 \\ \quad \text { TOTAL } & 41,951\end{array}$

17. Kay Words

55 MPH Speed Limit, Box-Jenkins Time Seri\&s Analysis, Intervention analysis, compliance, 18. Distribution Statement speeding involvement, FARS.

Document is available to the U.S. public through the National Technical Information Service, Springfield, Virginia 22161 


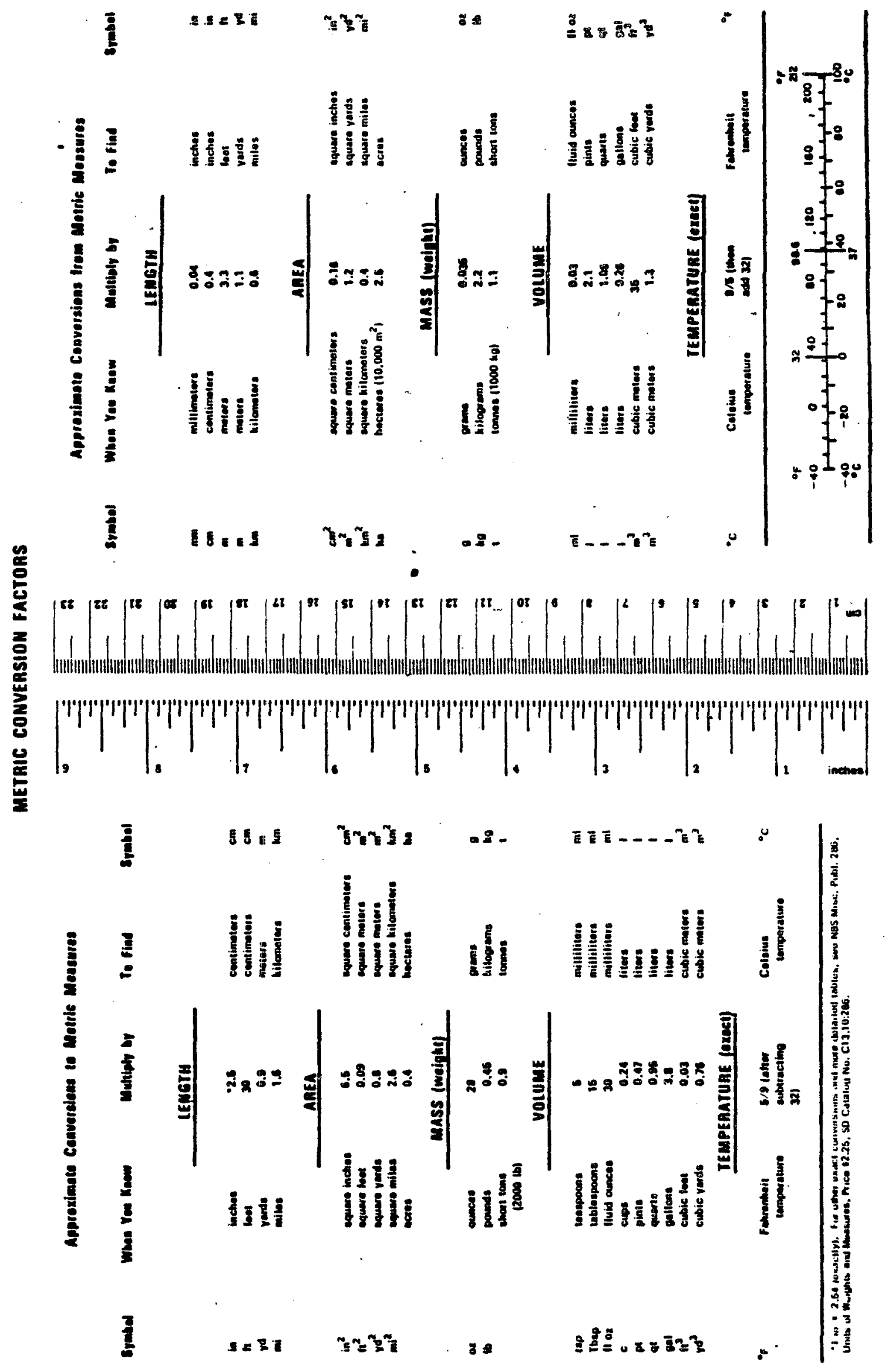




\section{SUMMARY}

A great many reasons have been put forth in attempting to explain the dramatic reduction in highway fatalities observed to have begun in January 1974, the official date of the imposition of the $55 \mathrm{mph}$ National Maximum Speed Limit (MMSL). The traffic safety literature contains a wide range of conflicting views as to the causal factors and magnitudes of these reductions in highway fatalities. These views range from the entire reduction to half of the reduction in highway fatalities being attributable to the lower sperds. A recent National Safety Council report $1 /$ claims that "reduced speeds still are a major factor in keeping down the death total, accounting for 44 percent of the difference between actual and expected totals for 1977. In numerical terms, there would have been 5,550 additional deaths in 1977, if there had been no $55 \mathrm{mph}$ laws, and consequently no reduced speeds."

The following report contains an analvsis of the life saving benefits resulting from the $55 \mathrm{mph}$ NMSL from 1974-1979. Monthly fatality data from 1970-1979 was used in a time series model to arrive at the estimated safety benefits (lives saved). The time series model relates changes in monthly fatalities to changes in monthly vehicle miles traveled, introduction of safety improvements and the implementation of the $55 \mathrm{mph}$ NMSL law.

Increases in highway fatalities in 1976-1979 compared to the 1974-1975 leve1 led to a detailed examination and analys is of the composition of these fatalities in order to determine possible causes for the increases. Based upon the available data, it was concluded that $55 \mathrm{mph}$ compliance had eroded somewhat in 1977 and 1978 thus resulting in some fatality increases.

The statistical time series model estimated annual life saving benefits as follows:

\section{LIVES SAVED}

1974

1975

1976

1977

1978

1979

TOTAL
7,532

7,532

7,216

6,794

6,423

$.6,454$

41,951 


\section{Introduction}

Six years have elapsed since the passage of the $55 \mathrm{mph}$ NMSL. A large number of studies regarding both the fuel saving and safety benefits of this law have been published. A review of the traffic safety literature reveals (1) a great variation in the estimated safety benefits of the $55 \mathrm{mph}$ NMSL, and (2) a lack of national level evaluations covering the total period since implementation.

The National Highway Traffic Safety Administration (NHTSA) strongly supports the $55 \mathrm{mph}$ NMSL and believes that it is one of the most effective countermeasures to have been used in reducing highway fatalities. In a memorandum by Joan Claybrook, NHTSA Administrator, dated July 6, 1977, life savings resulting from the $55 \mathrm{mph}$ NMSL were estimated to be between 4,000 and 5,000 per year based upon analyses up to that time. In October 1979, an NHTSA/FHWA Task Force was established to review all previous studies of the safety benefits of the $55 \mathrm{mph}$ NMSL and develop a technical report indicating a consensus of the safety benefits. Due to the lack of valid updated studies, and differences of opinion among task force members, only a survey report containina a range of life saving estimates was released. It is stronaly felt by the authors of this paper, that the safety benefits of the $55 \mathrm{mph}$ NMSL have been underestimated and it is the purpose of this paper to present the authors' views and conclusions.

\section{The Nature of Speed}

Any analysis of the effectiveness of a national speed reduction program such as the $55 \mathrm{mph}$ NMSL. should be accompanied by a discussion of the nature of speed and why one should expect reductions in fatalities and serious injuries resulting from a reduction in speed.

The traffic safety literature is replete with statistical analyses of the effect of speed and speed changes on accidents and injuries. A most widely cited study conducted by Solomon 2/ indicates that:

- Accident severity increased as speed increased, especially at speeds exceeding $60 \mathrm{mph}$.

$0 \quad$ The fatality rate was highest at very high speeds and lowest at about the average speed.

0 The accident involvement rate and the iniury and property damage rates were highest at very low speeds, lowest at about the average speed of all traffic and increased at the very high speeds, particularly at night. Thus, the greater the variation in speed of any vehicle from the average speed of all traffic, the sreater its chances of being involved in an accident.

One can conclude that as speed increases from the average speed, accident involvement rates and severity of injuries increase. It can be arqued that lower, un iform speeds, acceptable to the public and properly enforced, produce lower accident involvement rates. In addition, lower speeds also result in less severe injuries in the event of an accident. 


\section{A. National Experiment}

Since the imposition of the $55 \mathrm{mph}$ NMSL, the motor vehicle driving public has had six years to modify its driving behavior in keeping with the letter or spirit of the $55 \mathrm{mph}$ NMSL. If any modification of this behavior has taken place, it should be evident in the accident statistics collected during this time frame. Based upon the previous speed discussion, one should expect to observe national reductions in accidents, fatalities and injuries on those roads affected by the $55 \mathrm{mph}$ NMSL, along with reductions in speed.

One can view this as a simple pre/post experiment comparing accident statistics before and after the imposition of the law for significant changes in accident levels. However, many events took place during the six year period which precludes one from performing a simplistic analysis of speed reduction effectiveness. Specifically, highway, vehicle and driver improvements are continually being introduced in small increments and must be accounted for. Sufficiently large changes in the amount of travel as measured by vehicle miles traveled (VMT) have taken place over the period to be considered an important factor. From 1970-1979, VMT increased over 33.5\% (from 11,181 to 14,931 hundred million miles). From 1976 on, over half of the States repealed their mandatory motorcycle helmet laws resulting in a decrease in helmet use and an increase in the frequency of fatal head injuries $3 /$. The mix of vehicle size has been steadily changing from the larger fulT size cars down to the compact and sub-compact sizes thereby increasing the potential for increased severity of injury. Smaller cars offer less protection in the event of an accident. In addition to these confounding factors, accident data was not available for $55 \mathrm{mph}$ versus non $-55 \mathrm{mph}$ roads during the pre and post evaluation periods.

\section{Evaluation Approach}

A statistical approach using time series analysis 4/ was selected to derive an impact estimate of the $55 \mathrm{mph}$ NMSL as a life saving benefit. The period covered was the 1970 through 1979 time frame using national monthly fatalities as the impact measure. The baseline fatality level (non-55 mph period) for 1970 through 1973 was compared to the 1974 through 1979 fatality level (55 mph period) considering the confounding factors previously mentioned. The ultimate result was the development of a statistical evaluation model accounting for all of the factors considered to have significantly affected fatalities for the ten year period 1970 through 1979 to determine the reduction in fatalities attributable to the $55 \mathrm{mph}$ NMSL. Further detailed analys is was performed on the 1975 through 1979 data to adjust this estimate by the change in the degree of $55 \mathrm{mph}$ compliance which may have taken place during this time frame.

\section{Design Approach}

An ideal design approach for the evaluation model would produce a measure of the change in the fatal and injury accident levels before vs. after the imposition of the $55 \mathrm{mph}$ NMSL on two sets of roads: those roads whose speed limits were reduced to $55 \mathrm{mph}$ versus those roads whose speed limit remained unchanged, for the period 1970 through 1979. A comparison of the changes in level would then lead one to conclude whether the $55 \mathrm{mph}$ NMSL was an effective life saving countermeasure. 
This approach has been successfully applied to the analysis of State fatality data, where the data could be segregated by posted speed limit $5 /, 6 /$. However, in this case, since fatalities could not be separated by posted speed limit road, total fatalities were used as the impact measure. The assumption is that if any impact resulted from the imposition of the $55 \mathrm{mph}$ NMSL, it would be reflected as a change in the level of fatalities on 55 mph posted roads which are embedded in total fatalities. In addition, due to the lack of monthly injury accident data, it was not possible to measure the effect of the $55 \mathrm{mph}$ NMSL on the injury accident level.

\section{Evolution of the $55 \mathrm{MPH}$ Evaluation Model}

In the development of the evaluation model, fatalities were selected as the ultimate measure of the effectiveness of the $55 \mathrm{mph}$ NMSL. Input measures or explanatory variables were selected which logically affected fatalities. The purpose of this part of the analysis was to derive an evaluation model which yielded an estimate of the life saving benefits attributable to the $55 \mathrm{mph}$ NMSL. The final model related fatalities to factors affecting fatalities over time. Figure 1 is a graph of monthly fatalities with its 12 month moving average.

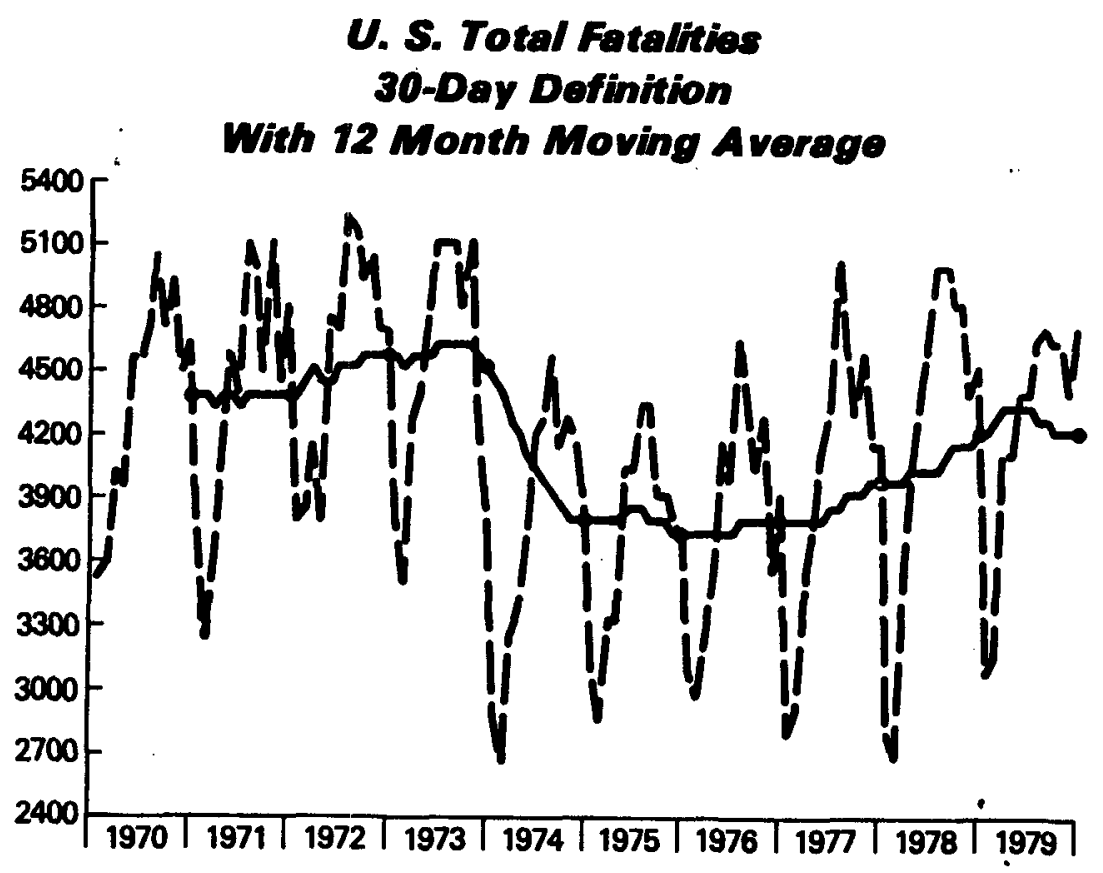

Two observations are immediately evident:

o The series is dominated by a distinct seasonal pattern (annual cycle), and

- There was an unusually large drop in fatalities hetween 1973 and 1974. 
An explanatory variable for the effect of the $55 \mathrm{mph}$ NMSL was introduced as an intervention variable in the form of zeros and ones to represent the absence or presence of the $55 \mathrm{mph}$ NMSL respectively. The effect of this intervention variable (SPEED) contains the sum total of all of the effects associated with the implementation of the $55 \mathrm{mph}$ NMSL, $i$.e., the effect due to enforcement, public information and education, etc., and not solely the effect of posted speed limit signs. Varying numbers of States reduced their maximum speed limits to $55 \mathrm{mph}$ between November 1973 and March 1974. Therefore, November 1973 was selected as the first date of intervention nationally.

Since different regions of the country experienced fuel shortages at different time periods with varying degrees, deriving a national estimate of the effect of the fuel shortage was considered unlikely. However, it was felt that the introduction of vehicle miles traveled (VMT) in the model would account for changes in exposure nationally, including the changes resulting from the fuel shortage. VMT data is generated by the States using motor vehicle gasoline revenue and consumption data and then supplied to the Federal Highway Administration (FHWA). Although not all States follow a uniform procedure in deriving these estimates, the data was assumed to be consistent between years.

As a result of the establishment of the U.S. Department of Transportation, automotive safety standards, driver education and training programs, highway design and construction improvements have had a very positive impact on the quality of travel in terms of safety. When one observes a steadily declining fatality rate (fatalities/100 million VMT) since 1968, it is reasonable to conclude that the introduction of these factors has contributed to this decline. A third variable was introduced to account for the differential changes between VMT and fatalities: This variable represents a measure of safety. An increase in VMT, accompanied by no change in fatalities will cause a reduction in the fatality rate per hundred million VMT, i.e., an increase in safety. Figure 2 is a graph of VMT and fatalities, indexed with 1967 as the base.

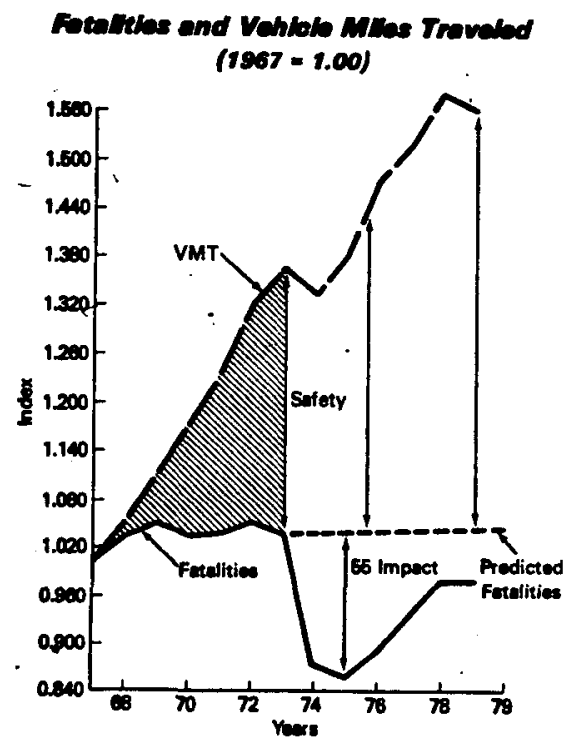


The shaded area from 1967 through 1973 represents the growth in VMT over and above the growth in fatalities, i.e., fatalities forestalled due to an increase in relative safety on the nation's roads (lower probability of a fatality per given VMT). In 1974, the large reduction in fatalities occurred independent from the increased safety on the roads. To illustrate this point, a fatality index projection is shown in Figure 2. It should be noted that the area between the VMT index and the fatality projection index (safety) was still increasing through the late 1970's. Critics of the $55 \mathrm{mph}$ NMSL have proposed that up to $50 \%$ of the fatality reduction in 1974 should be attributed to increased safety in the areas of motor vehicle and highway improvements. This does not follow from Figure 2, which seems to suggest that most if not all of the reduction in fatalities beginning in 1974 should be attributed to reduced exposure (VMT) in 1974 and the $55 \mathrm{mph}$ NMSL. In addition the safety effect was still increasina. In order to account for this safety effect, a third independent variable was introduced in the form of a fatality rate adjusted for the effect of the 55 mph NMSL imposition. A schematic of the traffic safety system is presented in Figure 3 .

FIGURE 3

\section{Fatality Systom}

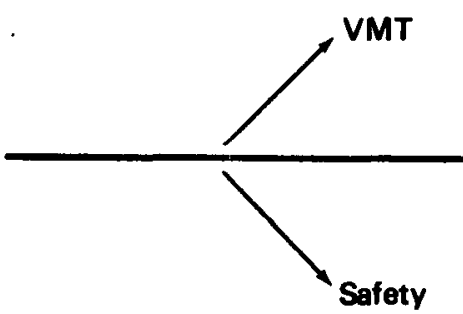

Fatalities

VMT and SAFETY operate in opposite directions in order to determine the fatality level.

The final evaluation model, combining fatalities as a function of VMT, SAFETY and SPEED was estimated. The estimate of life savings attributed to the $55 \mathrm{mph}$ NMSL was 627.65 per month (7,532 per year) for 1974-1979. The necessity of adjusting the estimate of $55 \mathrm{mph}$ impact comes from the fact that this estimate $(-627.65)$ represents an average over the total perind rather than a specific estimate for each year. In order to reflect the dynamics of traffic safety, the estimate was adjusted in order to account for variability in noncompliance between years. The analys is which follows uses fatalities by speeding involvement for the years 1975-1979 to adjust this estimate. 
Indications of Noncompliance with the 55 MPH. Speed Limit

A review of the fatalities in Figure 1 , shows that there has been an increase in 1977-1.979 compared to the 1974 through 1976 level. Many changes in the traffic safety level occurred during the 1977-1979 time frame including increasing noncompliance with the $55 \mathrm{mph}$ NMSL. This section will address the se issues in order to obtain the true effect of the $55 \mathrm{mph}$ NMSL during 1976-1979.

An analysis of fatalities was conducted using data from the Fatal Accident. Reporting System (FARS) in an effort to adjust the estimate of life savings for the effect of the $55 \mathrm{mph}$ NMSL derived in the previous section evaluation model. The reporting of the variable posted speed limit was not $100 \%$ complete as can be seen in Table 1 .

TABLE 1

Percent Reporting of Posted Speed Limited; FARS

KNOWN

UNKNOWN

1975

80.48

19.52

1976

80.42

19.58

1977

84.42

15.58

1978

87.73

12.27

1979

88.43

11.57

It is evident that the percent of known posted speed limit fatalities has been increasing over the years. For the purpose of this analysis, the unknown fatalities were redistributed into posted speed limit categories based on the distribution of the 80-88 percent known fatalities.

The redistribution of unknown posted speed limit fatalities yielded the following results in Table 2 .

TABLE 2

Fatalities due to speeding involvement $b_{j}$ posted speed limit

\begin{tabular}{cccc} 
Non-55 & Change & 55 & Change \\
\cline { 2 - 4 } 6,425 & & 7,806 & \\
6,584 & +159 & $8,7.22$ & +316 \\
7,300 & +716 & 8,544 & +422 \\
7,378 & +78 & 8,915 & +371 \\
7,679 & +301 & 8,884 & -31
\end{tabular}

Using the estimate for lives saved due to the $55 \mathrm{mph}$ NMSL, 627.65, yields an annual reduction of approximately 7,532 lives saved per year. This est imate can be adjusted by using the fatality changes on 55 mph roads from Table 2 for 1976-1979 to arrive at the benefits in Table 3 . 
TABLE 3

Lives saved due to $55 \mathrm{mph}$ MMSL

$\begin{array}{lr}1974 & 7,532 \\ 1975 & 7,532 \\ 1976 & 7,216 \\ 1977 & 6,794 \\ 1978 & 6,423 \\ 1979 & 6,454 \\ \text { Total } & 41,951\end{array}$

It should be noted that no decrease to the $55 \mathrm{mph}$ impact should be made to account for fatality increases either on roads posted less than $55 \mathrm{mph}$ or on $55 \mathrm{mph}$ roads where speeding was not a contributing factor. Therefore, for the six year period 1974-1979, almost 42,000 lives have been saved due to the slower, more uniform speeds resulting from the $55 \mathrm{mph}$ NMSL.

\section{Analysis of Speed and Speed Changes}

Adjustment to model estimates for changes in noncompliance were derived by analyzing changes in speeding involvement in fatal accidents. In order to corroborate these estimates, speed data was analyzed. When the $55 \mathrm{mph}$ NMSL was imposed, its effect should have been reflected in the speed statistics derived from the FHWA speed monitoring system. This system's data was used to analyze these speed changes over time. Annual speed certification data for FY 1968-1979 was obtained. The average speed and 85th percentile speed for the U.S. were used to determine:

1. If a considerable reduction in speed occurred timely to the imposition of the $55 \mathrm{mph}$ NMSL; and

2. If any changes in speeds can be shown for 1976-1.979, coinciding with changes in fatalities/fatality rate.

These two determinations, tied to comparable trends in fatalities, injuries, fatality rates and injury rates serve as a basis for validation of the estimate of the number of lives saved due to the $55 \mathrm{mph}$ NMSL.

Annual data for 1968-1978 was obtained for:

$\begin{array}{ll}0 & \text { average speed } \\ 0 & \text { 85th percentile speed } \\ 0 & \text { total fatalities } \\ 0 & \text { total injuries } \\ 0 & \text { injury rate } \\ 0 & \text { Interstate fatalities } \\ 0 & \text { Interstate injuries } \\ 0 & \text { Interstate fatality rates } \\ 0 & \text { Interstate injury rate }\end{array}$


Based on these data, the following observations were made:

- Average speeds, 85 th percentile speeds, the U.S. fatality rate and the Interstate fatality rate declined in 1974-1976, began to increase in 1977 .

- Total fatalities and Interstate fatalities declined in 1974-1975, began to increase in 1976.

- Total fatalities, fatality rate, Interstate fatalities, Interstate fatality rate, and Interstate injury rate exhibited a substantial drop (greater than ten percent) in 1974 from 1973 levels. The drop in average speeds was approximately five percent, for 85 th percentile speeds, it was approximately 2 percent.

A comparison of the fatality distributions by highway system demonstrated that beginning with 1974 there was a considerable drop in the fatality level. In addition, the greatest reductions in fatalities for 1974 occurred on those highway systems which would be most impacted by the $55 \mathrm{mph}$ NMSL -- the Interstate and other Federal Aid Primary Systems. Also, the increase in fatalities in 1977 is most evident in the change in fatalities on the Interstate --again the highway system most impacted by the $55 \mathrm{mph}$ NMSL and consequently most affected by increasing noncompliance.

\section{CONCLUSIONS}

The analysis of the impact of the $55 \mathrm{mph}$ NMSL has been conducted in three phases. Initially, the evaluation model was developed as a starting point to assess the magnitude of the effect of the reduced speed limit during 19741979. This pointed to the following conclusions:

- The introduction of safety improvements for the vehicle, driver and the environment has been generally effective in maintaining the level of fatalities, offsetting the expected increases due to increased exposure (VMT).

0 The initial impact of the $55 \mathrm{mph}$ NMSL was fairly constant for the years 1974-1975.

o During the period 1976-1979 there was upward growth in fatalities, as compared to 1974-1975.

The second phase of the analysis was an investigation of what factors contributed to the increase in fatalities in 1977-1978. This led to an analys is of fatalities due to speeding involvement by posted speed limit roads. From this analysis, adjustments were made to the evaluation model estimates, to account for the effect of noncompliance. The reconciliation of these factors appears in Table 4. 
TABLE 4

MODEL RECONCILIATION ( Iives saved)

55 mph NMSL

Noncompliance with 55

$\begin{array}{llrrrr}1974 & 1975 & 1976 & 1977 & 1978 & 1979 \\ 7,532 & 7,532 & 7,532 & 7,532 & 7,532 & 7,532 \\ & & -316 & -738 & -1,109 & -1,078 \\ & & 7,216 & 6,794 & 6,423 & 7,454\end{array}$

Total lives saved due to $55 \mathrm{mph}$ NMSL

The value 627.65 per month or an annual 7,532 in Table 17 represents the best estimate of the $55 \mathrm{mph}$ NMSL impact on the reduction in fatalities. It should be remembered that the adjustments made in phase two and reflecter in Table 17 are the result of the analysis of fatalities by speeding involvement and posted speed limit from FARS.

The third phase consisted of analyzing the speed monitoring data to investigate $55 \mathrm{mph}$ compliance over time. This analys is showed that:

o Between 1977-1978 there was a shift downward in compliance levels for the individual States.

$0 \quad$ The average speed and the 85th percentile speed, after reaching a low in 1976 began to rise in 1977.

o From 1976-1978, 32. States' average speed increased.

o From 1976-1978, 27 States' 85th percentile speed increased.

- From 1976-1978, 22 States experienced a decrease in compliance level and an increase in fatalities.

The results of the phase three analysis appear to validate the morel adjustments derived in phase two.

In conclusion, the $55 \mathrm{mph}$ MMSL is nne of the most effective countermeasures to have been used in reducing fatalities. The effect of the $55 \mathrm{mph}$ NMSL on fatalities depends heavily upon the compliance level present on the Nation's roads. 


\section{Bibliography}

1. Factors Contributing to the Decrease in Motor Vehicle Fatalities from 1973 to 1977, National Safety CounciT, May 18, 1979.

2. Solomon, D. Accidents on Main Rural Highways Related to Speed, Briver and Vehicle. Bureau of Public Roads, Washington, D. C., July 1964 .

3. The Effect of Motorcycle Helmet Usage on Head Injuries, the Effect of Usage Laws on Hel ret Hearing Rates - A Preliminary Report, January 1979

4. Box, G.E.P and Jenkins, G.M. Time Series Analys is Forecasting and Control. Holden-Day, 1970.

5. Johnson, P., Klein, T.M., Levy, P., Effect of the 55 mph Speed Limit Law on Fatal Crashes in Texas, DOT-HS-802-172, JuTy 1978.

6. Klein, T.M., Effect of the $55 \mathrm{mph}$ Speed Limit on Traffic Accidents in Illinois, DOT-HS-805-400, ApriT 1980. 